\title{
The Situation and Countermeasures of Accounting Teaching in China
}

\author{
Jinyu Yang ${ }^{1}$ \\ ${ }^{1}$ College of Economics and Management, Southwest University, Chongqing, China \\ Correspondence: Jinyu Yang, College of Economics and Management, Southwest University, Beibei District, \\ Chongqing, China. Tel: 86-135-9417-0299. E-mail: 14562715@qq.com
}

Received: March 25, 2015

Accepted: April 14, 2015

Online Published: April 17, 2015

doi:10.5430/ijfr.v6n2p160

URL: http://dx.doi.org/10.5430/ijfr.v6n2p160

\begin{abstract}
The economic development proposes new issues for accounting teaching, which not only relies on educators' own perfection as well as the joint efforts of the accounting practitioners and social parties. The author briefly described the new circumstances the accounting education faces in recent years, summarized the characteristics of accounting teaching and proposed countermeasures to these accounting teaching issues
\end{abstract}

Keywords: accounting teaching, education reform, teaching method

\section{Introduction}

For a long time, accounting undergraduate education at University has a widespread tendency, that is to implement a personnel training and teaching mode oriented on discipline supply. In such mode, teachers apply students with specialized accounting knowledge according to subject classification, so that students can use this knowledge to solve accounting application problems in real work in their future careers. However, this accounting education ignores the response to the value demands of stakeholder. Also, educators fail to communicate with the industry and the accounting profession in process of defining objectives and ability. Teaching contents and methods ignore the capacity needs of job market for accounting graduates, and show students with accounting rules deviated from business practices. Many people think that schools fail to provide necessary learning contents for the characteristics of current accounting practitioners, especially the necessary professional judgments in their practice process, which is one of the main causes of corporate accounting scandals. Thus there is an increasing requiring for accounting education reform. In accounting academics, more and more scholars pay attention to accounting education. Accounting education encounters not only challenges and opportunities, but also many problems.

\section{The Circumstance of China's Accounting Education}

\subsection{The Global Economic Integration Requiring Accounting Internationalization}

Global economic integration is the trend of world economic development in the 21st century. Global economic integration brings huge challenges to China's accounting education. A large number of multinational companies pack into China and localized operate their business, which greatly increases the demand for senior management personnel and high-tech personnel familiar with the rules of world trade in aspects of finance, management, trade, legal, accounting and so on. China's education market looks to further increase, thus many countries take various measures to attract Chinese students to study abroad. Moreover, government relaxes the conditions for foreign institutions to enter China and cooperate with local institutions. These higher education institutions have a strong attraction, and directly compete with schools in our country, which challenges our high education. No doubt, the competition in accounting education market is a rare development opportunity for us. The introduction of foreign educational resources helps us to learn the experience from developed countries, and combined with our national conditions, which promotes China's accounting education, especially the development of accounting education in university.

\subsection{The Influence of Knowledge Economy on Accounting Circumstance}

Economic and social development increasingly dependents on knowledge accumulation and application of effective information, as well as human's wisdom and innovation. A survey shows that the main factors affecting accounting mainly involves knowledge economy, information technology, and economic reform, etc., in which the knowledge economy take the first place. The complex working environment of accountants, combining with modern computer 
networks and accounting tools, require accounting personnel with high-quality and comprehensive ability. The application of modern scientific technology increases the risk, hence, security accounting data is worthy of attention.

\subsection{Barriers and Exchange between Western and Eastern Culture}

Any economic and legal policies have deep cultural roots. Including idea, value orientation, way of thinking, behavior, language and customs, etc., the culture environment of accounting has an important impact on the formation and development of the accounting model system. It restricts the value, ethic and belief of the accounting staffs. A cultural orientation affects the development and direction of the country's accounting theory and practice. The culture is an important determinant to form a national accounting system.

Comprehensively analyzing cultures in different countries, it is clear to see that there is a big culture difference. In recent years, China's social and cultural environment is gradually changing. The concept of freedom, individualism and legality, and the democracy and equality are strengthened. The culture of competition and credit, and the rational, scientific and independent spirits are raised. All of them will have a profound impact on the construction of China's accounting system. Confucian culture is adept in the induction and analogy. We continue to carry forward this way of thinking, and get rid of the drawbacks in limiting people's innovative thinking. In this regard, the cultural influence is deep-seated.

\section{The Problems and Countermeasures in China's Accounting Teaching}

\subsection{Accounting Education Goals}

The undergraduate education should be distinguished to two levels -- elite and public education. For public education, it should focus on training applied talents. After accumulation for years and strict selection, most undergraduate students are full of wisdom, and have realistic idea for their future. They know where to go next in the end, how to properly take a key step in their lives, need to make their own design. Thus, during college, they are often able to determine whether to continue their studies, or directly to find positions after graduation. According to their different options and actual circumstances, they can be divided into two categories. The former can be educated as elite. Colleges create certain conditions for their advance studies. The latter can be educated as application-oriented talents and engage in enterprise as senior management.

Postgraduate education should be distinguished to two levels--applied education and research education. Although graduate education gives priority to cultivate research talent in colleges and universities, this trend will change with the expansion of graduate enrollment. For student with the potential to continue their studies, they are trained as research personnel to obtain a $\mathrm{PhD}$ degree or engage in higher education or scientific research work. For other students, training them as senior applied talents can serve as the best choice.

The educational goals and methods of traditional accounting can not meet the needs of the development and changes of the accounting profession. The purpose of accounting education is not just to let students who just go into accounting profession to become professional accounting workers, but to make them to have ability of learning and innovation as accounting staffs. Thus, lifelong learning and reskilling are important.

\subsection{Examination and Evaluation System}

The ultimate goal of accounting education is to produce qualified "product" that is to train qualified accounting personnel (Kavanagh and Drennan, 2008). Whether the "product" meet the "customers"' needs better, of course, there is an evaluation criteria. At present, schools predominate in the evaluation of students. However, schools overemphasize comprehensive development during the evaluation. The goal of evaluation is not associated with that of employers. Schools examine achievements only by the scores of compulsory courses, which leads to the result that students with others ability including practical ability take an inferior position. These students with extensive knowledge and practical ability usually are welcomed by employers. The schools only focus on final paper scores ignoring actual ability and daily performance. The exams are used to assess the extent in which students grasp the knowledge. Students, who do not possess very in-depth knowledge, make a frantic last-minute effort to get good results.

Therefore, we need to adjust the methods of student evaluation. The school dominant evaluation should be transformed to market demand oriented. We should investigate the market demand for accounting professionals and the employers' requirements for accounting professionals. This survey is the first choice of the reform of the examination evaluation system, which is the subject we will continue to study in depth. At present, we suggest to do the followings in the examination evaluation:

1) Examinations diversification-- The written and oral tests are combined. Schools focus on measure students' 
knowledge understanding and the ability of digesting what they have learned.

2) Combining usual test and final exam-- The evaluation is not all decided by the final exam. More emphasis is put on usual tests, which are not necessarily in the form of paper test. Case studies, brainstorming and other means also work.

3) Question types in test break the tradition-- The traditional question types include multiple-choice questions, multiple-choice questions, judgments, essay questions, calculation problems, and business problems, etc.. These kinds of questions mainly test the extent of their understanding and memorizing of books knowledge, and ignore testing their application ability. There is little scope for initiative even in the essay questions.

\subsection{Teaching Method}

China's traditional teaching mode lags behind the times. This model focuses on inculcation and absorption of knowledge, while ignoring the application of knowledge. It does not exercise and develop the judgment and decision-making ability of students. To change this situation, we should learn from the advanced teaching mode and teaching methods of foreign universities.

Case teaching has been a weak link in accounting education. Although many colleges and universities also attach great importance to case teaching, a number of factors limit the development of case teaching. Case teaching can improve comprehensive analysis and professional judgment of the students. To ensure the effectiveness of case teaching, case teaching should at least include cases in fields of financial accounting, financial management, auditing and management accounting. To improve case teaching, we should concentrate on the part of case collection and collation, which requires instructors with higher quality. The instruction giving of teachers is the main way of teaching in the past. Although it is one of the most efficient methods, it does not seem to work all the time. This teaching method not only has poor effect, and it is easy to be imitated by those low-cost ways of teaching. Teachers will find that in the competitive environment, the traditional teaching has lost superiority. Traditional teaching and extreme standardized examination system are not sufficient to provide students with adequate preparation to face fierce market competition. To survive, the traditional education should continue to develop the way of teaching and integrate learning method and assessment system, including studies of business case, as well as other innovative teaching methods. Only to find a distinctive teaching way, traditional universities can survive.

\subsection{Changing Teaching Content}

Teaching students how to learn is more important than merely reciting facts. Students should acquire written and oral communication skills, develop ability of effective collective cooperation, stimulate a deep dialectical thinking, raise good quality under pressure, and encourage innovation spirit of applying new technology (Albrecht and Sack, 2000). The accounting teaching in American college improve students' viability through a variety of ways, for example, providing internship opportunities, advisory programs, examples teaching and other effective content. In addition, some creative way or content, like example assignments, group discussions, classroom communication, video reports, writing comments, company visits, and business liaison, will be very effective. The classroom instruction combined with practical experience is also very beneficial.

At present, the content of our accounting teaching lags behind. The contents of many courses repeat over and over again. Students are hard to fully digest what they haVE learnt because of heave academic burden. The educational system of foreign university is generally three years, 8 courses each year, and for a total of about 24 courses. In China, the courses of accounting major are over 50. Our accounting major should learn from the advanced experience of foreign countries and adjust the curriculum as soon as possible. In our country, to maintain a course curriculum of long hours, we can reduce the time of teaching and enhance students' self-learning and discussion.

There is a certain deviation in accounting textbooks writing. The authors stress on accounting system interpretation while ignoring theoretical analysis, which makes the students' ability of application difficult to improve. The absence of strict censorship leads to low quality of numerous national accounting textbooks. To change this situation, (a) it is necessary to transform the original system and teaching materials of textbooks, and achieve the internationalization as soon as possible; (b) part of the curriculum can directly use original textbooks, especially some relatively weak curriculum, such as management information system, accounting information system and so on. We should deliberate before the introduction of foreign original textbooks.

\subsection{Improve Teachers' Quality}

Professors will lose a lot of students, if they do not thoroughly understand the society. Students will transfer to adult education college where professionals will teach them. The latest understanding of reality means that in an 
increasingly globalized market, the professors should have interest in the world market. Courses they giving should base on an international vision. Faculties must be the loyal readers of the latest research projects and business magazines. To maintain awareness of the society is also reflected in developing and maintaining close contact with business community. These links include occasional internships, consulting projects and services, or scientific cooperation. Each accounting program should have a positive faculty development plan. In order to survive at the University, the accounting programs only continue to develop their expertise. They can not take the same road of their contenders, and meet parents' expectations of students. The accounting programs and their teachers at University should firstly decide what is the most competitive advantage of their teams and then try to maintain that advantage. Senior managements in such school believe that to stand in the forefront of teaching, professors must be very active in both academic and professional fields. They have to keep close contact with the business community to understand the latest developments. Professors of accounting must continue to learn new skills. The courses curriculum must continue to be adjusted. The students also have to keep making progress. The educational methods must continue to be improved and innovated. At the same time, we need the support of teaching participants, as well as the decrease of education cost.

At this stage, teaching situation is rarely taken into consideration in the management approach at our colleges and universities. Both professional titles, or a variety of treatments, depend more on teachers' research achievements. Teachers' effort of cases design gets sound teaching effect in classroom, attracting favorable comment from students. Most schools reward teachers for three kinds of activities: teaching, academic research and social service. Although successful teaching includes many factors, such as course plan, teaching method and student assessment, traditional educations usually only evaluate and reward for teaching method. Furthermore, although there are many types of academic research, traditional educations usually only evaluate and reward for professors' published articles in academic journals.

\section{Conclusion}

Nowadays, the economic globalization is moving forward. With the increasing complexity of the business environment, we bring forth new ideas in business models and transaction methods. As a result of that, accounting standards constantly change. In addition, accounting operations require more professional judgment on the basis of international convergence. With the development of information technology, traditional business of information record in accounting is fully implemented by computers. On the other hand, the role of accounting information, acting as comprehensive diagnosis and assisted decision for business, is growing day by day. The accountants need to use accounting information to participate management decision-making. The results of decision-making will be interpreted into business information which other people in the organization can easily understand. To better carry out these functions, accountant need to have a good professional judgment, information analysis and communication skills, which results in a more broad and complex capacity needs for accountants. However, whether those graduates, trained from accounting education, can adapt to the ability needs of the accounting profession? This directly affects whether accounting profession can work for social organizations and economic development in the future, and whether accounting profession can attract the attention of young students. It is a great event that concerns the success or failure of accounting education. Whether these "products" of accounting education are accepted by society is the final evidence to examine the quality of undergraduate education. Whether these graduates can contribute to the society? An important prerequisite is that graduates we train can meet ability needs of the society for accounting profession.

\section{Acknowledgements}

The authors would like to acknowledge generous support from "the Fundamental Research Funds for the Central Universities (Grant No: SWU140933).

\section{References}

Albrecht, W. S., \& Sack, R. J. (2000). Accounting Education: Charting the Course through a Perilous. Accounting Education Series, 16, 1-72. Retrieved from http://aahq.org/pubs/AESv16/toc.htm

Kavanagh, M., \& Drennan, L. (2008). What Skills and Attributes Does an Accounting Graduate Need? Evidence from Student Perceptions and Employer Expectations. Accounting and Finance, 48, 279-300. http://dx.doi.org/10.1111/j.1467-629X.2007.00245.x 